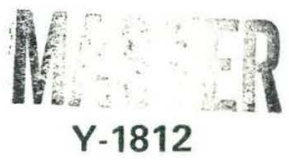

\title{
DETERMINATION OF TUNGSTEN BY SOLVENT EXTRACTION AND ATOMIC ABSORPTION SPECTROSCOPY
}

R. W. Morrow

\section{UNION CARBIDE CORPORATION}

\section{NUCLEAR DIVISION}

\section{OAK RIDGE Y-12 PLANT}

operated for the ATOMIC ENERGY COMMISSION under U. S. GOVERNMENT Contract W-7405 eng 26

UNION

CARBIDE
OAK RIDGE Y-12 PLANT

P. O. Box $Y$

OAK RIDGE, TENNESSEE 37830 


\section{DISCLAIMER}

This report was prepared as an account of work sponsored by an agency of the United States Government. Neither the United States Government nor any agency Thereof, nor any of their employees, makes any warranty, express or implied, or assumes any legal liability or responsibility for the accuracy, completeness, or usefulness of any information, apparatus, product, or process disclosed, or represents that its use would not infringe privately owned rights. Reference herein to any specific commercial product, process, or service by trade name, trademark, manufacturer, or otherwise does not necessarily constitute or imply its endorsement, recommendation, or favoring by the United States Government or any agency thereof. The views and opinions of authors expressed herein do not necessarily state or reflect those of the United States Government or any agency thereof. 


\section{DISCLAIMER}

Portions of this document may be illegible in electronic image products. Images are produced from the best available original document. 
Printed in the United States of America. Available from National Technical Information Service

U.S. Department of Commerce

5285 Port Royal Road, Springfield, Virginia 22151

Price: Printed Copy \$3.00; Microfiche \$0.95

This report was prepared as an account of work sponsored by the United States Government. Neither the United States nor the United States Atomic Energy Commission, nor any of their employees, nor any of their contractors, subcontractors, or their employees, makes any warranty, express or implied, or assumes any legal liability or responsibility for the accuracy, completeness or usefulness of any information, apparatus, product or process disclosed, or represents that its use would not infringe privately owned rights.

Reference to a company or product name does not imply approval or recommendation of the product by Union Carbide Corporation or the U S Atomic Energy Commission to the exclusion of others that may meet specifications. 


\title{
DETERMINATION OF TUNGSTEN BY SOLVENT EXTRACTION AND ATOMIC ABSORPTION SPECTROSCOPY
}

\author{
R. W. Morrow
}

Oak Ridge Y-12 Plant

P.O. Box Y, Oak Ridge, Tennessee 37830

operated for the U.S. ATOMIC ENERGY COMMISSION bY UNION CARBIDE CORPORATION-NUCLEAR DIVISION under Contract W.7405-eng-26



Date Issued - January 11, 1972 


\section{DISTRIBUTION}

\section{Atomic Energy Commission.}

Keller, C. A.

Zachry, D. S., Jr

Oak Ridge Gaseous Diffusion Plant

Jordan, R. G.

Wilcox, W. J., Jr

Oak Ridge Y-12 Plant

Barton, T. H., Jr

Bernander, N.K.

Briscoe, O. W.

Burditt, R. B.

Burkhart, L. E.

Charles, J. W.

Denny, A. (3)

Dill, M. S.

Hemphill, L. F.

Kahl, K. G.

Keith, Alvin

Mc Lendon, J. D.

Mitchel, G.W.

Morrow, R. W. (10)

Pierce, G. V.

Schreyer, J. M.

Stephens, L. A., Sr

Weathersby, W. E.

Wesley, R. L.

Yaggi, W. J.
$Y-12$ Central Files (5)

$Y-12$ Central Files (master copy)

$Y-12$ Central Files (route)

$Y-12$ Central Files $(Y-12 R C)$

Paducah Gaseous Diffusion Plant

Winkel, R. A.

The University of Tennessee

Dean, J. A.

In addition, this report is distributed in accordance with the category UC-4, Chemistry, as given in the "USAEC Standard Distribution Lists for Unclassified Scientific and Technical Reports", TID-4500. 


\section{ABSTRACT}

A method is described for determining 25 to $1,000 \mu \mathrm{g} / \mathrm{gm}$ quantities of tungsten in tantalum by solvent extraction and atomic absorption spectroscopy. The tungsten is complexed with tolvene-3,4-dithiol (4-methyl-1,2-dimercaptobenzene) and extracted into butyl acetate. The extract is nebulized into a nitrous oxide-acetylene flame, and the tungsten content determined by the atomic absorption at 2,551.4 A. Ten samples (two aliquots each) can be analyzed in six hours. The relative limit of error for a single determination by the proposed procedure under routine laboratory conditions is \pm 9.5 percent ( 95 percent confidence level). 


\section{CONTENTS}

SUMMARY ....................... 5

INTRODUCTION ...................... 6

EXPERIMENTAL WORK. . . . . . . . . . . . . . . . . . 7

Apparatus ......................... 7

Reagents and Solutions . . . . . . . . . . . . . . . . 7

Tolvene-3,4-Dithiol, One Percent (wt/vol) . . . . . . . . . 7

Standard Tungsten Stock Solution $(1,000 \mu \mathrm{g} / \mathrm{ml})$. . . . . . . . 7

Standard Tungsten Addition Solution $(100 \mu \mathrm{g} / \mathrm{ml})$. . . . . . . . 7

Tantalum Metal for Matrix Preparation . . . . . . . . . 7

Titanium Sponge . . . . . . . . . . . . . . . . 7

Procedure .......................... 8

Preparation of Standards . . . . . . . . . . . . . . 8

Results and Discussion .................... 9

Calibration Curve and Sensitivity. . . . . . . . . . . . 9

Optimum Absorption Conditions . . . . . . . . . . . . . 9

Interferences ...................... 9

Precision and Accuracy ................ 10

REFERENCES ........................ 11 


\section{SUMMARY}

A rapid, sensitive, and accurate method to determine microgram quantities of tungsten in tantalum is presented. The samples are dissolved in nitric and hydrofluoric acids and the tungsten quantitatively extracted from the tantalum matrix into butyl acetate as the tolvene-3,4-dithiol complex. The organic phase is then nebulized into a fuel-rich nitrous oxide-acetylene flame with the tungsten atomic absorption at 2,551.4 A determined above a butyl acetate blank.

The procedure has the inherent sensitivity and selectivity of atomic absorption plus the added enhancement derived from using organic solutions. The sensitivity was found to be $1.2 \mu \mathrm{g} / \mathrm{ml} / 1$ percent absorption when using $5 X$ scale expansion. Using similar instrumental conditions the sensitivity with aqueous solutions is about $4 \mu \mathrm{g} / \mathrm{ml} / 1$ percent absorption. The procedure was found to possess precision and accuracy that compared favorably with the more costly spectrophotometric method. 


\section{INTRODUCTION}

Microgram quantities of tungsten are commonly determined by the thiocyanate and tolvene-3,4-dithiol (often called "dithiol") spectrophotometric methods. (1-3) Although these methods are precise and sensitive, they are time consuming and subject to interferences. Experience with other metals suggested that a more rapid determination of microgram quantities of tungsten in tantalum metal might be accomplished by atomic absorption.

Up to the present time only limited information has appeared concerning the determination of tungsten by atomic absorption. (4) The high detection limit of tungsten in aqueous solution and its low concentration in the tantalum samples received necessitated using solvent extraction to concentrate and isolate the element for determination by atomic absorption. In the proposed procedure the tantalum sample is dissolved in nitric and hydrofluoric acids and the tungsten (VI) is reduced to tungsten (V) with titanium (III). The metal is then complexed with tolvene-3,4-dithiol in $10 \mathrm{~N}$ hydrochloric acid and extracted into butyl acetate. The tungsten content of the butyl acetate phase is then determined by aspirating into a nitrous oxideacetylene flame and measuring the atomic absorption at 2,551.4 $\mathrm{A}$. 


\section{EXPERIMENTAL WORK}

\section{APPARATUS}

All atomic absorption measurements were made with a Techtron Model AA-4 atomic absorption spectrometer equipped with a nitrous oxide-acetylene burner, a shielded tungsten hollow-cathode lamp, and a $10 \mathrm{mv}$ recorder. The instrumental conditions employed are given in Table 1. The baseline (zero absorption) was determined by continuous nebulization of butyl acetate between samples. With the fuel conditions given in Table 1 and with butyl acetate nebulizing, the red interconal zone was 1 to $2 \mathrm{~cm}$ high.

\section{REAGENTS AND SOLUTIONS}

Table 1

INSTRUMENTAL CONDITIONS FOR DETERMINATION OF TUNGSTEN IN TANTALUM

\begin{tabular}{lc}
\hline \multicolumn{1}{c}{ Conditions } & Value \\
\hline Wavelength (A) & $2,551.4$ \\
Slit Width $(\mu)$ & 100 \\
Lamp Current $(\mathrm{mA})$ & 27 \\
Spectral Beam Height & \\
$\quad$ Above Burner (mm) & 6 \\
Nitrous Oxide Flow (I/min) & 6.7 \\
Acetylene Flow (I/min) & 7.0 \\
Gain with 5X Scale Expansion & 4 \\
\hline
\end{tabular}

Tolvene-3,4-Dithiol, One Percent (wt vol)

Dissolve 20 grams of sodium hydroxide pellets in about 500 milliliters of water. Break two 5-gram vials of tolvene-3,4-dithiol under the surface and add 8 milliliters of thioglycolic acid as an oxidation inhibitor. Stir thoroughly to dissolve, dilute to one liter, and transfer to polyethylene bottles for storage. This solution is stable for at least a month when kept under refrigeration.

Standard Tungsten Stock Solution $(1,000 \mu \mathrm{g} / \mathrm{ml})$

Transfer 1.7945 grams of reagent grade sodium tungstate dihydrate $\left(\mathrm{Na}_{2} \mathrm{WO}_{4} \cdot 2 \mathrm{H}_{2} \mathrm{O}\right)$ to a liter volumetric flask, dissolve in distilled water, and dilute to volume. Store in a polyethylene bottle.

Standard Tungsten Addition Solution $(1.00 \mu \mathrm{g} / \mathrm{ml})$

Transfer 10 milliliters of the tungsten stock solution to a 100 -milliliter volumetric flask and dilute to volume with distilled water.

Tantalum Metal for Matrix Preparation

Tungsten-free tantalum or tantalum of known tungsten content must be used.

Titanium Sponge

Tungsten-free titan ium must be used, 


\section{PROCEDURE}

Transfer the sample containing from 25 to $1,000 \mu \mathrm{g}$ tungsten and weighing not more than one gram to a 70-milliliter platinum crucible. Add 5 milliliters of 48 percent hydrofluoric acid and cover the crucible with a platinum lid. Add concentrated nitric acid in 5-drop increments until dissolution is complete. A one-gram sample will usually require about 25 drops of nitric acid. Wash the lid with three milliliters of concentrated sulfuric acid, allowing the washings to pass into the crucible. Fume. the sample on a hot plate (surface temperature $500^{\circ} \mathrm{F}$ ) for 30 minutes after the evolution of heavy white vapor begins. If a slight white precipitate forms, discontinue heating. If evaporation is carried further, heavy precipitation of hydrated tantalum oxide occurs and the sample should be discarded. After fuming, cool the sample to room temperature and add 10 drops of 48 percent hydrofluoric acid. Cautiously add 15 milliliters of concentrated hydrochloric acid and transfer the sample to a 100 -milliliter volumetric flask containing $0.2 \mathrm{gram}$ of tungsten-free titanium sponge. Use an additional 25 milliliters of hydrochloric acid to wash the crucible and add the washings to the flask. After the titanium has dissolved, heat the sample in a water bath $\left(75-80^{\circ} \mathrm{C}\right)$ for seven minutes. The solution should have a medium purple coloration.

Add 20 milliliters of one percent toluene-3,4-dithiol solution and heat in a water bath $\left(75-80^{\circ} \mathrm{C}\right)$ for 20 minutes while swirling the flask occasionally. Cool to room temperature and pipette 10 milliliters of butyl acetate into the flask. Stopper and shake for 2 minutes and allow 10 minutes for phase separation. The butyl acetate layer containing the tungsten will be a dark blue-green. With a wash bottle, slowly add 3:1 hydrochloric acid down the neck of the flask until the organic phase is just below the ground glass region. Nebulize the sample and determine the tungsten absorbance above the butyl acetate background signal. Determine the tungsten content of the sample by comparison with a standard of similar concentration.

\section{PREPARATION OF STANDARDS}

Matrix matching is used to assure that tungsten is extracted to the same extent from both standard and sample solutions. Tantalum matrix solutions are prepared by dissolving the same weight of tantalum as taken in the sample. Known amounts of the tungsten addition solution are added after the tantalum solution is fumed and the first addition of hydrochloric acid is made. The tungsten content of the butyl acetate phase will be equal to the amount added plus any initially present in the tantalum. The tungsten content of the sample of tantalum metal powder used for matrix preparation as determined by the toluene-3,4-dithiol spectrophotometric procedure was $24 \mu \mathrm{g} / \mathrm{gm}$. 


\section{RESULTS AND DISCUSSION}

\section{Calibration Curve and Sensitivity}

When percent absorption at 2,551.4 A was plotted against the concentration, the resulting curve had a zero intercept and was linear over the range of 10 to at least $70 \mu \mathrm{g} \mathrm{W} / \mathrm{ml}$ of butyl acetate. However, when absorbance was used, the curve was concave downward indicating that the relatively low absorbance values taken with $5 \mathrm{X}$ scale expansion are in a non-Beer's Law region. The 2,551.4 A line was chosen in preference to the recommended line at 4,008.8 A because of the superior signalto-noise ratio observed using the conditions in Table 1.

The sensitivity at 2,551.4 A expressed as the concentration of tungsten necessary to produce a one percent absorption signal is $1.2 \mu \mathrm{g} / \mathrm{ml}$ of butyl acetate, which is approximately a factor of four lower than the sensitivity using aqeuous solutions. The noise level under optimum operating conditions was usually less than 0.5 percent of full scale.

\section{Optimum Absorption Conditions}

The variation in absorbance of the 2,551.4 A tungsten line with spectral beam height is shown in Figure 1 . The maximum absorbance at each acetylene flow is seen to occur

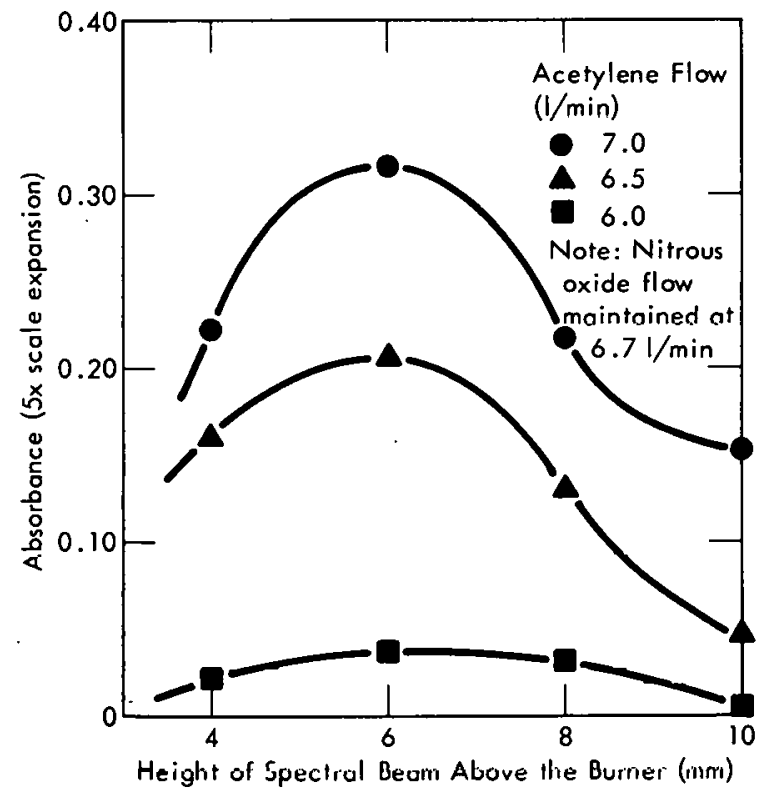

Figure 1. TUNGSTEN ABSORBANCE AT 2,551.4 A AS A FUNCTION OF FLAME REGION. at approximately the same region in the flame. The change in absorbance with flame region at a constant oxidant-tofuel ratio indicates that the ground-state tungsten atoms are not evenly distributed throughout the red interconal zone. The relatively rich flame needed to ellicit maximum absorbance indicates that a reducing environment is necessary for main tenance of a suitable ground state atom population. The use of acetylene flows greater than 7 liters/minute resulted in rapid carbon deposition along the burner slot with little increase in absorption.

\section{Interferences}

This method seems to be relatively free of interferences from the quantity of elements commonly found in high-purity tantalum metal. Although toluene-3,4-dithiol will complex many heavy metals, the majority of these (ie, iron and copper) are insoluble in butyl acetate. (5) It is unlikely that trace amounts of any metals that may extract with tungsten would cause any spectral interference. 
Under the conditions described, tungsten is quantitatively extracted with one equilibration. Only a small quantity of tantalum was found to coextract; apparently, most of it is complexed with fluoride and remains in the aqueous phase. Molybdenum was found to be about 10 percent coextracted with tungsten. Most of the molybdenum. (VI) could be reduced to molybdenum (III) without forming a stable extractable complex. (5)

\section{Precision and Accuracy}

The precision of the proposed procedure was determined by calculating the relative percent limit of error of a single determination using a control sample analyzed on a routine basis in the laboratory. The mean tungsten content of the control sample determined from sixty three analyses (two aliquots each) was $328 \mu \mathrm{g} / \mathrm{gm}$. The limit of error of a single determination computed at the 95 percent confidence level was $\pm 31 \mu \mathrm{g} \mathrm{W} / \mathrm{gm}$. The relative limit of error of a single determination is \pm 9.5 percent .

The accuracy of the method was evaluated through comparison of results with those obtained by the toluene-3,4-dithiol spectrophotometric procedure. Table 2 gives the comparison of results for ten tantalum metal samples of varying tungsten content. The tungsten content by both methods was computed from an average of two aliquots. The results by atomic absorption generally agree within two to four percent of the spectrophotometric values. Statistical analyses of the mean difference (atomic absorption minus spectrophotometric) of results obtained for samples of similar tungsten. content indicates that no bias exists. The mean difference for five samples in the $370-410 \mu \mathrm{g} W / \mathrm{gm}$ range was $8 \mu \mathrm{g}$ $\mathrm{W} / \mathrm{gm}$ and the limit of error of the mean difference was $23 \mu \mathrm{g} \mathrm{W} / \mathrm{gm}$. Results for six samples in the $80-130 \mu \mathrm{g}$

Table 2

DETERMINATION OF TUNGSTEN IN TANTALUM METAL

\begin{tabular}{|c|c|c|c|}
\hline Sample & $\begin{array}{c}\text { Atomic } \\
\text { Absorption (1) } \\
\text { ( } \mu \mathrm{g} \mathrm{W/gm} \mathrm{Ta)}\end{array}$ & $\begin{array}{c}\text { Spectrophotometric (1) } \\
(\mu \mathrm{g} \mathrm{W} / \mathrm{gm} \mathrm{To})\end{array}$ & $\begin{array}{c}\text { Difference } \\
(\%) \\
\end{array}$ \\
\hline 1 & 396 & 410 & -3.4 \\
\hline 2 & 387 & 377 & 2.6 \\
\hline 3 & 112 & 114 & -1.8 \\
\hline 4 & 116 & 120 & -3.3 \\
\hline 5 & 404 & 374 & 7.5 \\
\hline 6 & 127 & 125 & 1.6 \\
\hline 7 & 109 & 114 & -4.4 \\
\hline 8 & 212 & 209 & -1.4 \\
\hline 9 & 83 & 87 & -4.6 \\
\hline 10 & 127 & 129 & -1.6 \\
\hline
\end{tabular}

(1) Average of two aliquots. $\mathrm{W} / \mathrm{gm}$ range were $-2 \mu \mathrm{g} \mathrm{W} / \mathrm{gm}$ and \pm 3 $\mu \mathrm{g} \mathrm{W} / \mathrm{gm}$ respectively. 


\section{REFERENCES}

(1) "1964 Book of ASTM Standards", Part 32, pp 741-744; American Society for Testing and Materials, Philadelphia, Pennsylvania.

(2) Sandell, F. B.; Colorimetric Determination of Traces of Metals, pp 835-891; , Interscience, New York, New York.

(3) Greenberg, P.; Anal Chem, 29, p 896 (1957).

(4) Slavin, W.; Atomic Absorption Spectroscopy, pp 178-181; Interscience, New York, New York.

(5) Sandell, F. B.; Colorimetric Determination of Traces of Metals, pp 651-652; Interscience, New York, New York. 